\title{
Sudden bradycardia and impending cardiac arrest by intra-myometrial vasopressin in laparoscopic myomectomy: a case report and review of literature
}

\author{
Monika Madaan ${ }^{1 *}$, Priyanka Baghotia ${ }^{1}$, Neha Soni ${ }^{1}$, Samir Shankar Raj ${ }^{2}$ \\ ${ }^{1}$ Department of Obstetrics and Gynaecology, ESIC Hospital, Manesar, Haryana, India \\ ${ }^{2}$ Department of Anaesthesiology, ESIC Hospital, Manesar, Haryana, India \\ Received: 18 September 2020 \\ Revised: 01 November 2020 \\ Accepted: 02 November 2020

\section{*Correspondence:} \\ Dr. Monika Madaan, \\ E-mail: monikarajivgaur@gmail.com \\ Copyright: (C) the author(s), publisher and licensee Medip Academy. This is an open-access article distributed under \\ the terms of the Creative Commons Attribution Non-Commercial License, which permits unrestricted non-commercial \\ use, distribution, and reproduction in any medium, provided the original work is properly cited.
}

\begin{abstract}
Vasopressin has long been used in myomectomy to decrease blood loss. Its efficacy is beyond doubt. But at the same time it is known to cause some of the serious cardiovascular side effects. We here report a case of severe bradycardia and impending cardiac arrest caused by intra-myometrial infiltration of $12 \mathrm{U}$ of vasopressin and present a review of literature.
\end{abstract}

Keywords: Vasopressin, Myomectomy, Bradycardia, Cardiac arrest

\section{INTRODUCTION}

Vasopressin, a posterior pituitary hormone is used for reducing blood loss during myomectomy from more than 60 years. Although intra-myometrial vasopressin results in very good surgical hemostasis it may cause adverse cardiac events like bradycardia, arrhythmia, cardiac arrest and pulmonary oedema and lethal catastrophe if not diagnosed and managed soon. ${ }^{1-4}$ We report a case of successful resuscitation following bradycardia and impending cardiac arrest by intra-myometrial injection of vasopressin in a case of laparoscopic myomectomy.

\section{CASE REPORT}

A 27 years old nulliparous woman, a case of primary infertility with posterior wall intra-myometrial fibroid was posted for operative hysterolaparoscopy. She had no past medical or surgical history. All her hematological, biochemical investigations and electrocardiography (ECG) was normal. The woman was ASA grade I and after thorough evaluation she was taken up for surgery after 6 hours of fasting. She was monitored by 5 lead ECG, pulse oximeter, ETCO2 and non-invasive blood pressure monitor. Baseline vitals were pulse- $82 /$ minute, blood pressure (BP)-120/76 mmHg, O2 saturation $100 \%$ with normal sinus rhythm on ECG. She was preloaded with 1 liter ringer lactate and combined spinal epidural anesthesia was given in L3-4 space and level of T6 achieved. Dexmedetomidine infusion was started with a loading dose of $50 \mathrm{mcg}$ in $10 \mathrm{~min}$ followed by infusion of 50 $\mathrm{mcg} / \mathrm{hr}$. She was supplemented with injection fentanyl 50 mcg intravenous (IV) and injection propofol $40 \mathrm{mg}$ IV. Initially hysteroscopy was performed with $6 \mathrm{~mm}$ diagnostic rigid hysteroscope which showed normal uterine cavity and normal bilateral ostia. Afterwards laparoscopy was performed with supraumbilical primary port and three accessory $5 \mathrm{~mm}$ ports at intra-abdominal pressure of $15 \mathrm{mmHg}$, abdominal cavity visualized which showed a large bosselated subserosal fibroid of 7 by $7 \mathrm{~cm}$ arising from posterior wall of uterus at the level of isthmus. Bilateral tubes and ovaries were normal, and free spill of dye seen bilaterally on chromopertubation test. Till this time woman had normal vitals, SPO2 and ETCO2. For 
reducing blood loss during myomectomy, $180 \mathrm{ml}$ of intramyometrial vasopressin injected in dilution of $20 \mathrm{U}$ in 300 $\mathrm{ml}$ (12 $\mathrm{U}$ in total) slowly after negative aspiration. Within one minute of vasopressin infiltration patient developed sudden bradycardia with heart rate dropping to $25 \mathrm{bpm}$, hypotension as evidenced by systolic blood pressure of 70 $\mathrm{mm} \mathrm{Hg}$ and signs of impending cardiac arrest. The patient had normal SPO2 and normal ETCO2 at this time also indicating adequate perfusion. There was intense facial pallor and peripheral pulses were not palpable. Pnemoperitoneum was deflated, injection atropine $0.6 \mathrm{mg}$ was given intravenously and two more doses were given at interval of 30 seconds and 1 minute respectively. Intravenous crystalloids were given fast and patient was revived with heart rate picking upto $80-90 \mathrm{bpm}$ and blood pressure values improving to $90 / 60 \mathrm{~mm} \mathrm{Hg}$. SPO2 and ETCO2 were normal throughout the surgery. Although the patient was in regional anesthesia we could not assess the consciousness level of the patient as she was given fentanyl, propofol and dexmedetomidine initially in view of laparoscopic surgery. We waited for around half an hour after resuscitation and proceeded with open myomectomy. Postoperatively patient was shifted in HDU in stable condition with normal vitals, SPO2 100\% without O2 and normal findings of chest and CVS examination. The patient was discharged on 5th postoperative day in good condition.

\section{DISCUSSION}

Vasopressin is an anti-diuretic hormone and has a strong vasoconstrictive effect on smooth muscles. It is a direct vasoconstrictor and also acts by stimulating contraction of myometrial cells in the uterus via its action on V2 receptors. The half-life of vasopressin is 24 minutes as compared to very short life of other vasoconstrictors like epinephrine (2 minutes) and oxytocin (10 minutes), making it a superior agent for achieving hemostasis. . $^{5-7}$

Various studies have demonstrated proven efficacy of vasopressin in varied dosages in decreasing blood loss during myomectomy.

The first of these studies have been reported by Dillon et al almost sixty years ago on 20 patients in whom vasopressin was used to decrease blood loss associated with gynecologic surgery. ${ }^{8}$ They used $4 \mathrm{U}$ as the total maximum dose diluted in $20 \mathrm{ml}$ of saline $(0.2 \mathrm{U} / \mathrm{ml})$. They injected 5-10 $\mathrm{ml}$ (1 to $2 \mathrm{U}$ ) at the beginning of the surgery, repeated the injections as needed, but did not exceed a total cutoff of $4 \mathrm{U}$. The authors monitored the ECG and vital signs and found no evidence of abnormalities or untoward events while still noting a marked decrease in blood loss. A recent study has shown the efficacy of vasopressin in reducing blood loss during my-omectomy. ${ }^{9}$ The mean EBL was $321.8 \pm 246.0 \mathrm{ml}$ in control group as compared with $147.8 \pm 171.8 \mathrm{~mL}$ in the group using vasopressin $(\mathrm{p}<0.001)$. A randomized controlled trial $(\mathrm{RCT})$ by Frederick et al showed that vasopressin use during laparoscopic myomectomy (20 $\mathrm{U}$ in $20 \mathrm{ml}$ normal saline) was associated with a significant reduction in mean blood loss (225 versus $675 \mathrm{ml}, \mathrm{p}<0.001)$, and mean hemoglobin (Hb) (1.7 versus $5.3 \mathrm{~g} / \mathrm{dL}, \mathrm{p}<0.001)$ and hematocrit (HCT) drop $(5 \%$ versus $13 \%, \mathrm{p}<0.001)$ as compared with placebo. ${ }^{10}$ The latest Cochrane database review showed that vasopressin use is associated with a reduction in blood loss of between 392.51 and $507.49 \mathrm{ml}$ during abdominal myomectomy and between $121.73 \mathrm{ml}$ and $172.17 \mathrm{ml}$ during laparo-scopic myomectomy. ${ }^{11}$

Although vasopressin is a very good hemostatic agent but at same time there are published case reports of ad-verse cardiac effects by vasopressin like bradycardia, hypotension, arrhythmias, atrioventricular block, pulmonary edema, and even cardiac arrest. In Greece, France and Italy for example, vasopressin has been withdrawn long ago in response to safety concerns.

We performed a search on PubMed and Google scholar using terms vasopressin, myomectomy, cardiac complications, bradycardia and hypotension.

Table 1 shows the various case reports with their complications, dosages of vasopressin used and the final outcome.

Barcroft et al reported a case of acute pulmonary edema which developed in a case of laparoscopic myomectomy after infiltration of $20 \mathrm{U}$ of vasopressin. ${ }^{1}$ This case initially developed bradycardia and hypotension which was managed with glycopyrrolate, ephedrine and crystalloids. The patient settled down but at extubation was found to have pink frothy sputum and desaturated to $89 \%$ suggesting that she developed acute pulmonary edema. She was managed with IV furosemide and diamorphine and recovered after stay in intensive care unit (ICU).

Hobo et al reported a case of bradycardia and cardiac arrest caused by infiltration of $56 \mathrm{ml}$ of $20 \mathrm{U}$ of vasopressin diluted in $200 \mathrm{ml}$ saline $(0.2 \mathrm{U} / \mathrm{ml}){ }^{2}$ The patient was managed with ephedrine, atropine and cardiac massage and had uneventful recovery.

Hung et al described two cases of bradycardia followed by cardiac arrest and pulmonary edema after local infiltration of 6-10 $\mathrm{ml}$ of dilute vasopressin $(2 \mathrm{U} / \mathrm{ml})$ during an open myomectomy. ${ }^{3}$

Lee et al reported a case of severe bradycardia and cardiac arrest during robotic assisted myomectomy after infiltration of vasopressin in doses of 20 IU (20 IU diluted in $40 \mathrm{ml}$ of normal saline). ${ }^{4}$ The patient was success-fully revived with atropine $0.5 \mathrm{mg}$, reversal of Trendelenburg position and supportive care. They attributed bradycardia to physiologic effects of vasopressin, pneumoperitoneum in steep Trendelenburg position for laparoscopy, shoulder braces for robotic surgery which add to carotid sinus compression and lowered sympathetic activity leading to bradycardia. 
Table 1: Case reports showing complications with different vasopressin doses and outcome.

\begin{tabular}{|c|c|c|c|c|}
\hline Case report & Vasopressin dose & Route of surgery & Complication & Final outcome \\
\hline Barcroft et al $^{1}$ & $20 \mathrm{U}$ & Laparoscopic & $\begin{array}{l}\text { Bradycardia, hypotension, } \\
\text { pulmonary edema }\end{array}$ & Recovered \\
\hline Hobo et $\mathrm{al}^{2}$ & $18 \mathrm{U}(0.5 \mathrm{U} / \mathrm{ml})$ & Laparoscopic & $\begin{array}{l}\text { Bradycardia, } \\
\text { cardiac arrest }\end{array}$ & Recovered \\
\hline Hung et $\mathrm{al}^{3}$ & $\begin{array}{l}12 \text { to } 20 \mathrm{U} \text { (in two } \\
\text { cases) }\end{array}$ & Abdominal & $\begin{array}{l}\text { Bradycardia, } \\
\text { cardiac arrest, } \\
\text { pulmonary edema }\end{array}$ & Recovered \\
\hline Lee et $\mathrm{al}^{4}$ & $20 \mathrm{U}$ & Robotic & $\begin{array}{l}\text { Bradycardia, } \\
\text { cardiac arrest }\end{array}$ & Recovered \\
\hline Nezhat et al ${ }^{15}$ & $4-5 \mathrm{U}(0.6 \mathrm{U} / \mathrm{ml})$ & Laparoscopic & $\begin{array}{l}\text { Bradycardia, hypotension, } \\
\text { pulmonary edema }\end{array}$ & Recovered \\
\hline $\begin{array}{l}\text { DeschampS et } \\
\text { al }^{16}\end{array}$ & $3 \mathrm{U}(0.5 \mathrm{U} / \mathrm{ml})$ & Abdominal & $\begin{array}{l}\text { Bradycardia, absent radial pulse, } \\
\text { AV block with bigemini }\end{array}$ & Recovered. \\
\hline $\begin{array}{l}\text { Muthukumar et } \\
\text { al }^{17}\end{array}$ & $4 \mathrm{U}(0.13 \mathrm{U} / \mathrm{ml})$ & Abdominal & $\begin{array}{l}\text { Bradycardia, hypotension, } \\
\text { absent peripheral pulses }\end{array}$ & Recovered \\
\hline Jayaram et al ${ }^{18}$ & $20 \mathrm{U}(0.1 \mathrm{U} / \mathrm{ml})$ & Laparoscopic & $\begin{array}{l}\text { Vasospasm, absent radial pulse, } \\
\text { stable ECG, } \\
\text { stable ETCO2 }\end{array}$ & Recovered \\
\hline Tulandi et al ${ }^{19}$ & $5 \mathrm{U}(0.5 \mathrm{U} / \mathrm{ml})$ & Laparoscopic & $\begin{array}{l}\text { Bradycardia, hypotension, AV } \\
\text { block, } \\
\text { pulmonary edema }\end{array}$ & Recovered \\
\hline 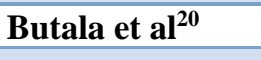 & $20 \mathrm{U}(1 \mathrm{U} / \mathrm{ml})$ & Abdominal & Bradycardia, hypertension & Recovered \\
\hline Kabade et al $^{21}$ & $8 \mathrm{U}(0.2 \mathrm{U} / \mathrm{ml})$ & Abdominal & $\begin{array}{l}\text { Bradycardia, hypotension, ST } \\
\text { segment depression, pulmonary } \\
\text { edema }\end{array}$ & Died \\
\hline Reiss et al $^{12}$ & $60 \mathrm{U}$ & Abdominal & $\begin{array}{l}\text { Absent peripheral pulses, severe } \\
\text { vasospasm, hypotension }\end{array}$ & Recovered \\
\hline
\end{tabular}

There are three kind of vasopressin receptors V1, V2 and V3. V1 and V2 receptors are located in the periphery whereas V3 receptors are found in central nervous system (CNS). Vasopressin produces generalized constriction of most blood vessels including coronary vessels resulting in increase in blood pressure. This sudden hypertension induces sympatho-inhibitory reflex by activating baroreceptors in aortic arch and carotid sinus resulting in lowering of cardiac contractility and heart rate. In the collecting tubules vasopressin acts on V2 receptors, causing water retention and it also acts on area postrema of brain to decrease cardiac output. Thus, there is decrease in heart rate and cardiac output as a result of coronary vasoconstriction, decreased blood flow, altered sympathetic tone and potentiated baroreflex in response to generalized vasoconstriction, which results in bradycardia, global hypotension and in severe cases cardiac arrest.

There are further risk factors associated with laparoscopy. Pneumoperitoneum with $\mathrm{CO} 2$ stretches the peritoneum which induces the vagal-mediated cardiovascular reflex leading to bradycardia. Trendelenburg position leads to increased venous return resulting in increase in stroke volume, and cardiac output thereby activating baroreceptors further which may lower the heart rate by diminishing sympathetic activity.

Our patient exhibited similar manifestations as pallor, sudden bradycardia and hypotension just after intramyometrial injection of vasopressin. Pale conjunctiva may be due to cutaneous vasoconstriction while brady-cardia is due to potentiated baroreflex and altered sympathetic tone. Hypotension may be due to decrease cardiac output, heart rate, altered sympathetic tone or because of peripheral vasopressin mimicking hypotension.

Treatment includes identification of this situation and cardiac life support measures oxygenation and atropine for bradycardia. Vasopressin has short half-life so early recognition and correct resuscitation results in successful outcome. Failure to identify this will lead to treatment with vasopressors which will worsen cardiac complications. 
There are some previous case reports of vasopressin overdose resulting in bradycardia and apparent hypotension that was treated with anticholinergic, inotropic, and vasoconstrictor drugs. Many of these cases subsequently developed pulmonary edema and acute STsegment changes suggestive of myocardial injury. These complications point to the fact that caution is required when using vasopressors in the treatment of vasopressininduced vasospasm. Treatment of bradycardia or hypotension after high-dose vasopressin with additional vasopressors and inotropes may be deleterious. Vasodilators such as nitroglycerine, atropine or increasing depth of anesthesia may theoretically have benefits in these situations. Noninvasive blood pressure measurement based on oscillometric waveform of blood flow may not be truly applicable in the setting of peripheral vasospasm and can lead to administration of additional inotropic drugs that can contribute to iatrogenic cardiovascular morbidity. It has also been proposed to measure central blood pressure using preoperative placement of central arterial catheter as peripheral vasospasm with central hypertension may give misleading clinical signs. ${ }^{12}$

In case invasive cardiac monitoring is not performed, palpable carotid pulses and normal value of positron emission tomography (PET) CO2 can help in differentiating peripheral vasospasm from global hypotension.

Contrary to all the above case reports, a study of the effects of vasopressin during laparoscopic myomectomyhas shown that it has less effect on larger and more central vessels. Although the study was conducted on nine patients, the concentration of vasopressin used was 4 IU (20 IU diluted in $100 \mathrm{ml}$ saline) and uterine blood flow was measured using transvaginal ultrasound evaluating arcuate artery and ascending branch of uterine artery while systemic blood flow was measured using transesophageal doppler evaluating aorta and measuring urine output. ${ }^{13}$

Another RCT by Cohen et al comparing different dilutions of vasopressin- $200 \mathrm{ml}$ of diluted vasopressin solution (20 $\mathrm{U}$ in $400 \mathrm{ml}$ saline), and $30 \mathrm{ml}$ of concentrated vasopressin solution (20 $\mathrm{U}$ in $60 \mathrm{ml}$ normal saline) found no significant difference in blood loss or change in HCT levels in both the groups. ${ }^{14}$

\section{CONCLUSION}

To summarize, vasopressin is cost effective agent in reducing blood loss during myomectomy the efficacy of which has been proven in well-designed RCT. But cardiovascular complications may occur with vasopressin use in varied dosages. The safe dose and concentration of vasopressin still needs to be determined. The amount of blood loss saved during myomectomy using vasopressin and the rare but potentially serious cardiovascular complications caused by its use needs to be weighed using risk benefit analysis in larger well randomized con-trolled trials. Whether we may consider invasive monitoring using central arterial line in women undergoing myomectomy with vasopressin use also needs to be addressed in future.

Funding: No funding sources

Conflict of interest: None declared

Ethical approval: Not required

\section{REFERENCES}

1. Barcroft JF, Kufaishi AA, Lowe J, Quinn S. Risk of vasopressin use: a case of acute pulmonary oedema, post intramyometrial infiltration of vasopressin in laparoscopic myomectomy. Brit Med J Case Rep. 2019; 12:e231-331.

2. Hobo R, Netsu S, Koyasu Y. Bradycardia and cardiac arrest caused by intramyometrial injection of vasopressin during a laparoscopically assisted myomectomy. Obstet Gynecol. 2009;113:484-6.

3. Hung MH, Wang YM, Chia YY, Chou YM, Liu K. Intramyometrial injection of vasopressin causes bradycardia and cardiac arrest- report of two cases. Acta Anaesthesiol Taiwan. 2006;44:243-7.

4. Lee GG, Baek SY, Kim TW, Jeong C. Cardiac arrest caused by intramyometrial injection of vasopressin during a robotic-assisted laparoscopic myomectomy. J Int Med Res. 2018;46(12):5303-08.

5. Baumann G, Dingman JF. Distribution, blood transport, and degradation of antidiuretic hormone in man. J Clin Invest. 1976;57:1109-16.

6. Heilborn H, Hjemdahl P, Daleskog M, Adamsson U. Comparison of subcutaneous injection and high-dose inhalation of epinephrine: implications for selftreatment to prevent anaphylaxis. J Allergy Clin Immunol. 1986;78:1174-9.

7. Dawood MY, Ylikorkala O, Trivedi D, Gupta R. Oxytocin levels and disappearance rate and plasma follicle-stimulating hormone and luteinizing hormone after oxytocin infusion in men. J Clin Endocrinol Metab. 1980;50:397-400.

8. Dillon TF, Marbury BE, Bonsnes RW, Douglas RG, $\mathrm{Du}$ Vigneaud V. Vasopressin as a hemostatic in gynecologic surgery; a preliminary report. Obstet Gynecol. 1958;11:363-71.

9. Protopapas A, Giannoulis G, Chatzipapas I, Athanasiou S, Grigoriadis T, Kathopoulis N, Vlachos DE, Zaharakis D, Loutradis D. Vasopressin during Laparoscopic Myomectomy: Does It Really Extend Its Limits? J Minim Invasive Gynecol. 2019;26(3):441-9.

10. Frederick J, Fletcher H, Simeon D, Mullings A, Hardie M. Intramyometrial vasopressin as a haemostatic agent during myomectomy. Br J Obstet Gynaecol. 1994;101(5):435-7.

11. Kongnyuy EJ, Wiysonge CS. Interventions to reduce haemorrhage during myomectomy for fibroids. Cochrane Database of Systematic Reviews 2014;8:CD005355.

12. Riess ML, Ulris JG, Pagel PS, Woehlck HJ. Severe vasospasm mimics hypotension after high dose 
intrauterine vasopressin. Anesth Analg. 2011;113:1103-5.

13. Shimanuki H, Takeuchi H, Kitade M, Kikuchi I, Kumakiri J, Kinoshita K. The effect of vasopressin on local and general circulation during laparoscopic surgery. J Minim Invasive Gynecol. 2006;13:190-4.

14. Cohen SL, Senapati S, Gargiulo AR, Srouji SS, Tu FF, Solnik J et al. Dilute versus concentrated vasopressin administration during laparoscopic myomectomy: a randomised controlled trial. Int J Obstet Gynaecol. 2017;124(2):262-8.

15. Nehzat F, Admon D, Nehzat CH, Dicorpo JE, Nezhat C. Life threatening hypotension after vasopressin injection during operative laparoscopy, followed by uneventful repeat laparoscopy. J Am Assoc Gynecol Laparosc. 1994;2:83-6.

16. Deschamps A, Krishnamurthy S. Absence of pulse and blood pressure following vasopressin injection for myomectomy. Can J Anaesth. 2005;52:552-3.

17. Muthukumar M, Mathews L, Vasantha NS, Anoop S. Intramyometrial vasopressin as a haemostatic agent: Is it really safe. Ind J Anaesth. 2015;59(1):51.

18. Jayaraman L, Sinha A, Punhani D. Intramyometrial vasopressin: Anesthesiologists' nightmare. J Anaesthesiol Clin Pharmacol. 2013;29:135-6.
19. Tulandi T, Beique F, Kimia M. Pulmonary edema: a complication of local injection of vasopressin at laparoscopy. Fertil Steril. 1996;66:478-80.

20. Butala BP, Shah VR, Parikh BK, Jayaprakash J, Kalo J. Bradycardia and severe vasospasm caused by intramyometrial injection of vasopressin during myomectomy. Saudi J Anaesth. 2014;8(3):396-8.

21. Kabade SD, Sachidananda R, Wilson E, Divater SB. Intramyometrial vasopressin: A fear for anesthetist? Saudi J Anaesth. 2017;11(4):494-5.

Cite this article as: Madaan M, Baghotia P, Soni N, Raj SS. Sudden bradycardia and impending cardiac arrest by intra-myometrial vasopressin in laparoscopic myomectomy: a case report and review of literature. Int J Reprod Contracept Obstet Gynecol 2020;9:5154-8. 